Адрес статьи / To link this article: http://cat.ifmo.ru/ru/2017/v2-i4/142

\title{
Использование мультимедийных технологий для интерактивной трехмерной реконструкции интерьера Трапезной палаты Феодоровского городка
}

\author{
Л.П. Сопроненко ${ }^{1}$, А.В. Лаврова ${ }^{1}$, А.А. Смолин ${ }^{1}$, В.Л. Мельников ${ }^{2}$ \\ ${ }^{1}$ Университет ИТМО, Россия \\ ${ }^{2}$ Музей-институт семьи Рерихов, Россия \\ so_lar@mail.ru, lavrova@corp.ifmo.ru, smolin@corp.ifmo.ru, msssm9@bk.ru
}

\begin{abstract}
Аннотация. Работа посвящена виртуальной реконструкции утраченных интерьеров Трапезной палаты Феодоровского городка в Царском Селе. Аутентичность реконструкции обеспечивается за счёт использования архивных материлов, фиксационных архитектурных обмеров и анализа аналогичных по стилю архитектурных объектов. Моделирование проводилось средствами Autodesk 3ds Max, после чего, в среде Unity было разработано интерактивное приложение для гарнитуры виртуальной реальности и создана браузерная версия на основе технологии WebGL с использованием библиотеки Three.js.
\end{abstract}

Ключевые слова: русский стиль, колористические решения росписей, своды Монье, виртуальные технологии, сохранение культурного наследия

\section{1. История Феодоровского городка}

Русский (Феодоровский) городок был построен в Царском Селе императорской резиденции близ Санкт-Петербурга по указу Николая II в 1913-1918 годах (проектирование велось с 1909 года). Основной идеей данного проекта стала визуализация истории русской архитектуры и искусства с XII по XVII века, чтобы жители столичного, во многом европейского, Петербурга, могли увидеть примеры подлинно русского стиля (рис. 1). Федоровский городок изначально несет в себе идею некой виртуальности, создания объекта, не существовавшего прежде в едином комплексе, но объединяющего в себе, с одной стороны, элементы аутентичного художественного языка, а с другой - самые современные на момент создания технологии.

Помимо собора, расположенного на берегу пруда, в представляющий собой замкнутый многоугольник комплекс, состоящий из нескольких корпусов различного назначения, входили: дома священников, дьяконов, причта и служб, выполненные в стилистике архитектуры Новгорода, Пскова и Костромы XVI-XVII веков, ворота, выполненные в стиле Владимиро-Суздальской архитектуры XII века. В целом, по выбору Николая II, композиция должна была напоминать Ростовский Кремль.

Центральным зданием городка стала Трапезная палата, для которой были выбраны мотивы Теремного дворца и Грановитой палаты Московского Кремля. Трапезная палата с Трапезным 
залом предназначалась для деятельности «Общества возрождения художественной Руси», проведения концертов и выставок предметов древнерусской старины, по образцам которых предполагалось создавать предметы дизайна. «Обществом...» для работы в Русском городке были привлечены владеющие национальным художественным языком архитекторы С. Кричинский, В. Суслов, П. Покрышкин, художники В. Васнецов, Н. Рерих, Г. Пашков.

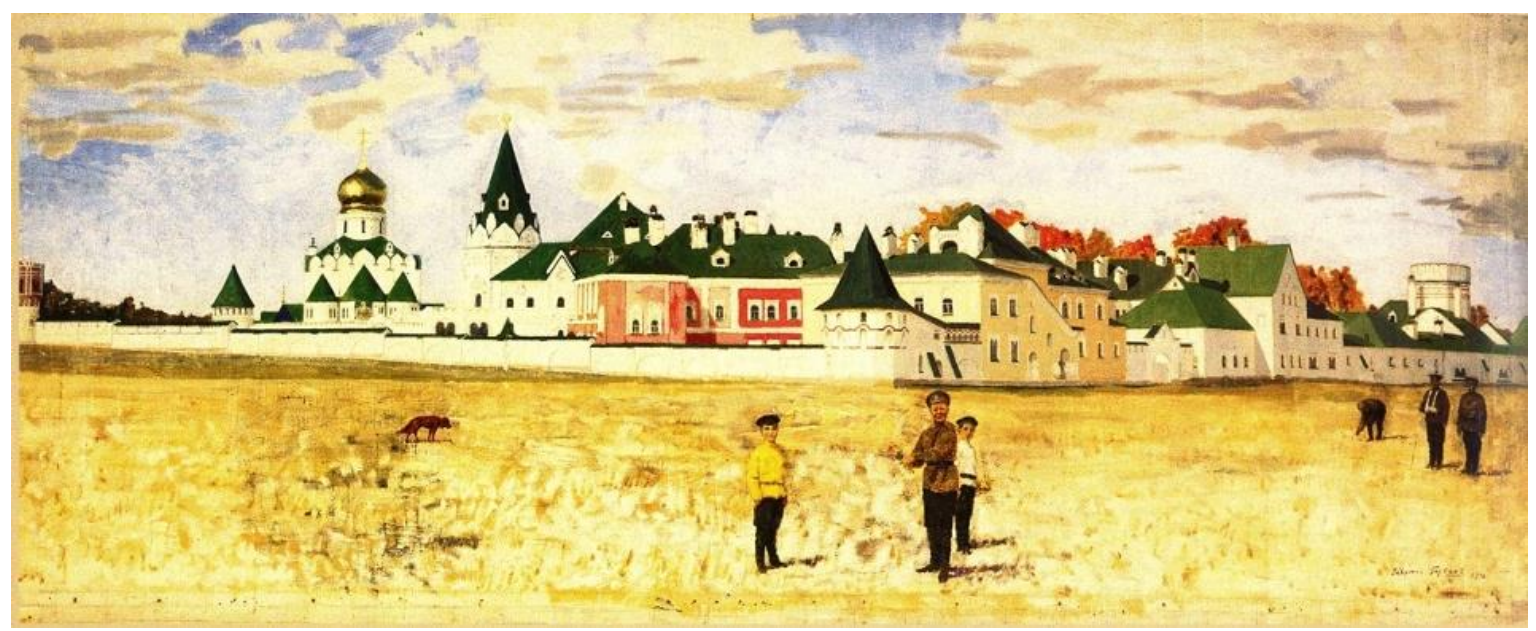

Рис. 1. «Русский городок и Феодоровский Государев Собор», Г.Н. Горелов, 1916 г.

Главным архитектором Трапезной палаты, как и всего комплекса Федоровского городка, был С. Кричинский, с именем которого во многом связана идеология Русского стиля. В феврале 1914 года С. Кричинский представил «Начала, послужившие основой для создания городка при Федоровском соборе», где изложил свой взгляд на развитие русской архитектуры [2]. Будущее Русского стиля он видел в том, чтобы, начав с копирования форм старинных памятников, прийти к созданию собственного художественного языка, созвучного эпохе. Прежде всего, новыми и актуальными в работах Кричинского были конструктивные решения на основе самых современных материалов. В Трапезной палате им был применен железобетонный каркас, заполненный кирпичной кладкой. Характерные для русского зодчества каменные своды в интерьере Трапезной он заменил ложными бетонными сводами по сетке (сводами Монье), в то время как междуэтажные перекрытия остаются плоскими (рис. 2).

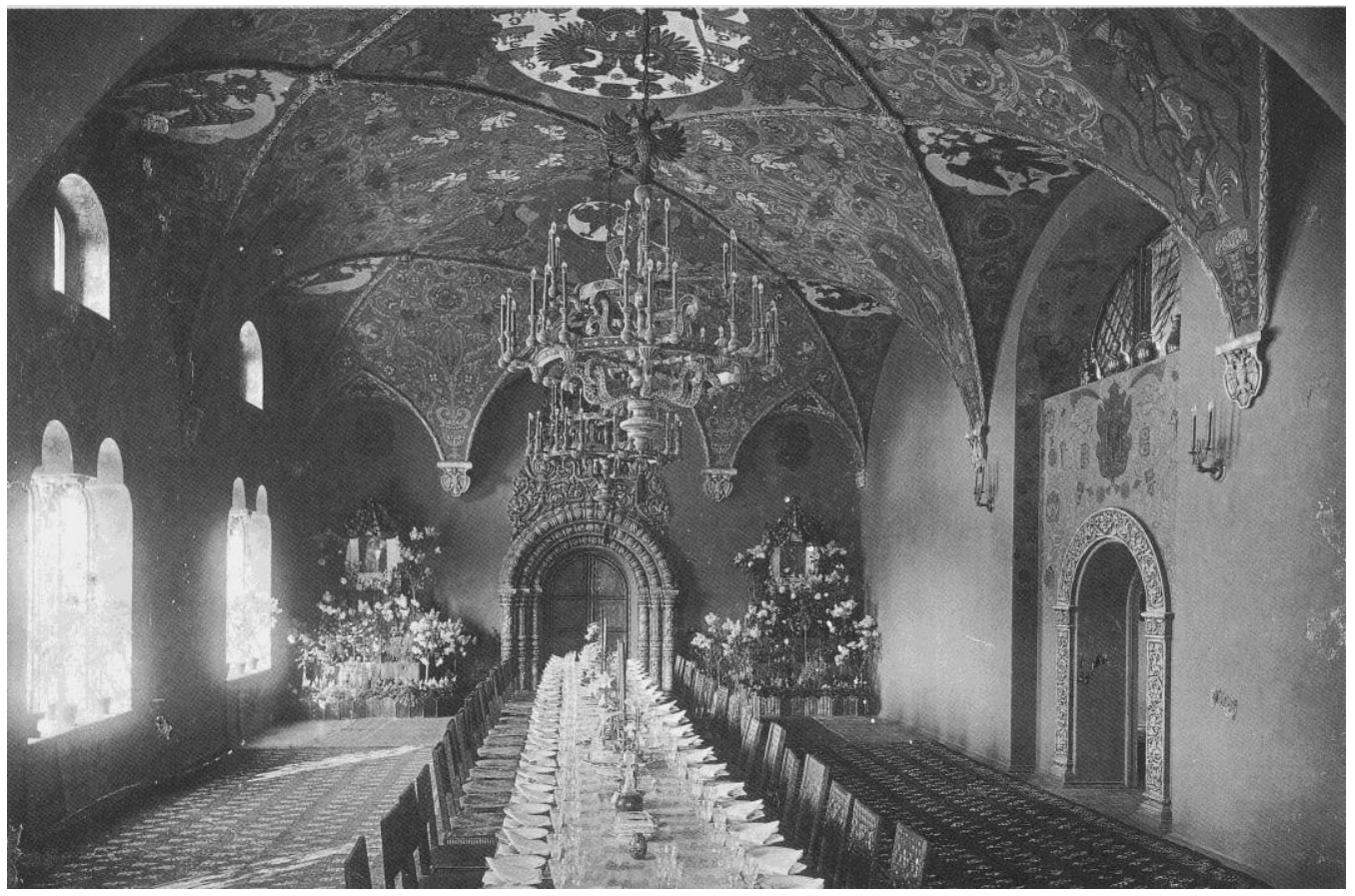

Рис. 2. Единственная сохранившаяся фотография интерьера Трапезной палаты, 1917 год

International Culture \& Technology Studies, Vol. 2, No. 4 
В интерьере Трапезной палаты большую роль играют росписи, сделанные по штукатурному слою. Художественным руководителем работ был В. Васнецов, выполнены росписи Г. Пашковым. За колористическую и стилистическую основу были взяты интерьеры Золотой и Столовой палат Теремного дворца Московского Кремля и палаты бояр Романовых [1].

История Феодоровского городка во многом повторяет историю страны. Законченный строительством в 1917 году, перед революцией, долгое время использовался по различному назначению, был сильно разрушен во время Второй мировой войны. В настоящее время здания, составляющие комплекс Федоровского городка, находятся в различном состоянии сохранности. Экстерьер Трапезной палаты сохранился частично, интерьер полностью утрачен (рис. 3). Сохранилась единственная черно-белая фотография интерьера, сделанная в 1917 году (рис. 2), а также описания из воспоминаний Ю. Ломана, сына главного организатора строительства Русского городка Д. Ломана.

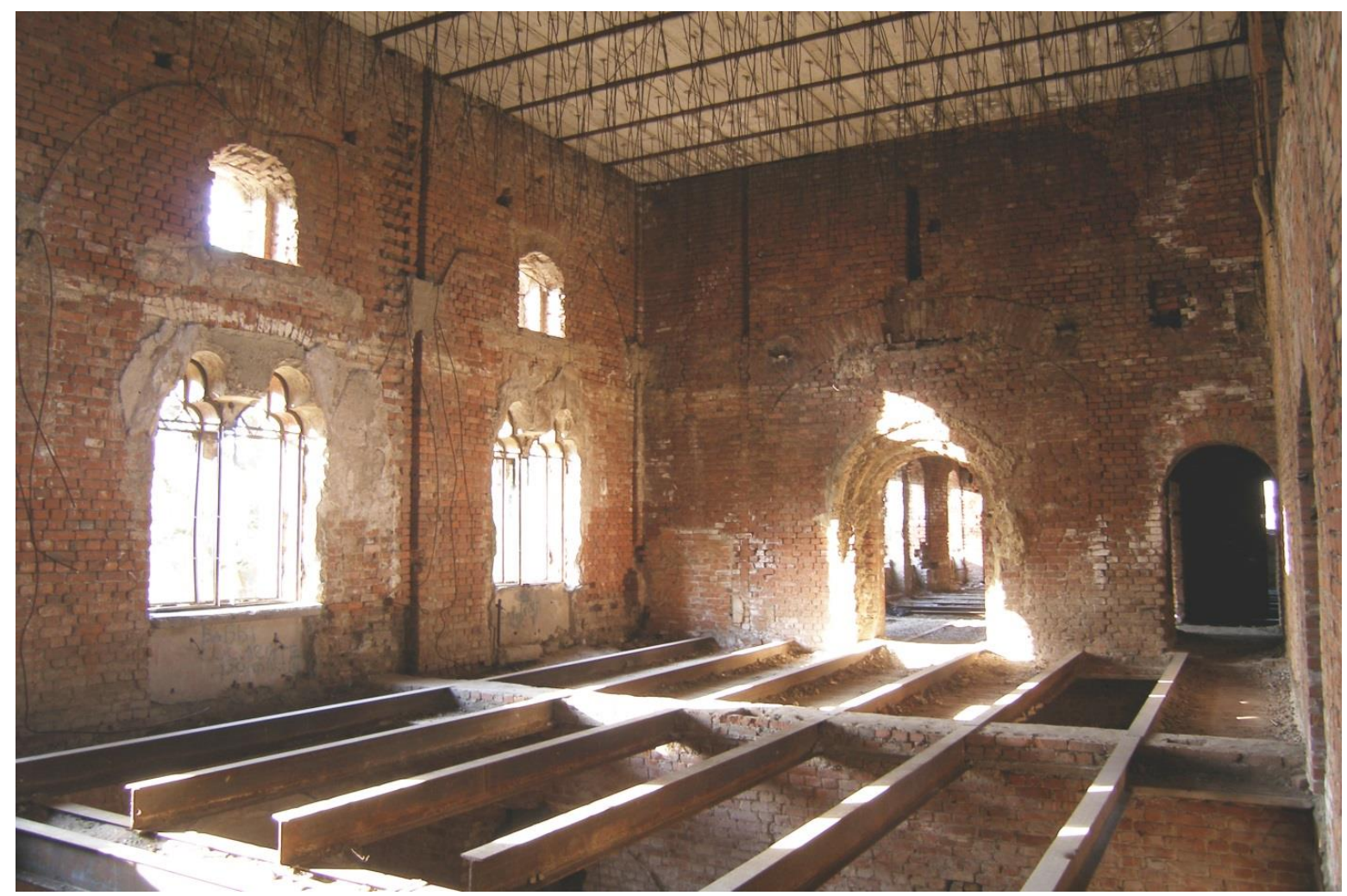

Рис. 3. Интерьер Трапезной палаты, 2008 год

\section{2. Реконструкция интерьера Трапезной палаты}

В 2004 году Царскосельской иконописной мастерской под руководством Г. Майоровой были сделаны прориси росписей Трапезной палаты. В 2009 году А. Крылов, академик, руководитель мастерской церковно-исторической живописи Санкт-Петербургской Академии художеств, организовал копирование сохранившихся фрагментов фресок силами студентов. Также были проведены фиксационные архитектурные обмеры мастерской И. Шмелева.

В 2015 году, на кафедре Графических технологий Университета ИТМО студенткой Е. Акулаевой была сделана виртуальная реконструкция интерьера Трапезной палаты [3]. В качестве инструментальных средств использовались следующие программы: Autodesk AutoCAD - работа с чертежами Трапезной палаты; Autodesk 3ds Max - создание 3d-модели интерьера Трапезной палаты; Adobe Photoshop - создание и обработка текстур для интерьера Трапезной палаты. Создание виртуальной реконструкции было разбито на несколько этапов:

1. Создание 3D-модели потолка главного зала Трапезной палаты;

2. Создание 3D-модели интерьера главного зала Трапезной палаты;

3. Создание разверток и текстур росписей потолка и стен главного зала;

4. Применение текстур и доработка интерьера Трапезной палаты. 
Так как до наших дней росписи главного зала Трапезной палаты не сохранились, цветовая палитра для текстур (рис. 4) подбиралась по реконструкциям фрагментов фресок, созданных иконописцами для Трапезной палаты, а также по сохранившимся фрескам памятников архитектуры того же времени и стиля постройки [4].

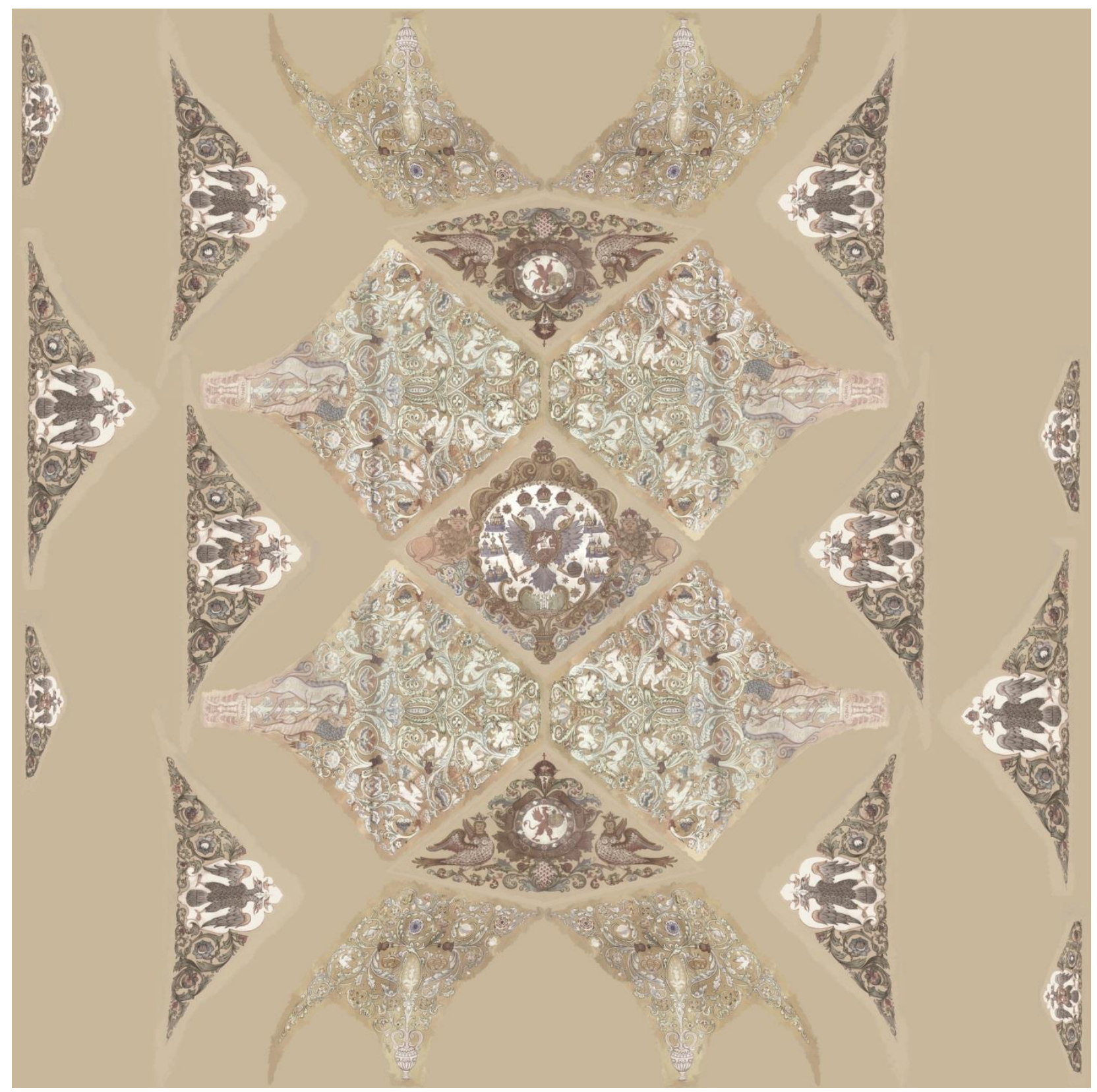

Рис. 4. Реконструкция росписей потолка главного зала Трапезной палаты

Перед началом трехмерного моделирования был проведен анализ воссозданных обмерных чертежей и разверток помещения. Планы архитектора Кричинского не сохранились, возникла проблема несовпадения воссозданных планов разных времен. Замерить геометрическую форму сводов невозможно, т.к. своды потолка были разрушены. После сопоставления размеров и разверток сводов потолка был создан оптимальный план зала и потолка Трапезной палаты, по которым в программе Autodesk 3ds Мах была создана трехмерная модель интерьера.

Для создания потолка главного зала Трапезной палаты был использован метод моделирования с помощью сплайнов, с последующим применением модификатора «Surface» (рис. 5). 


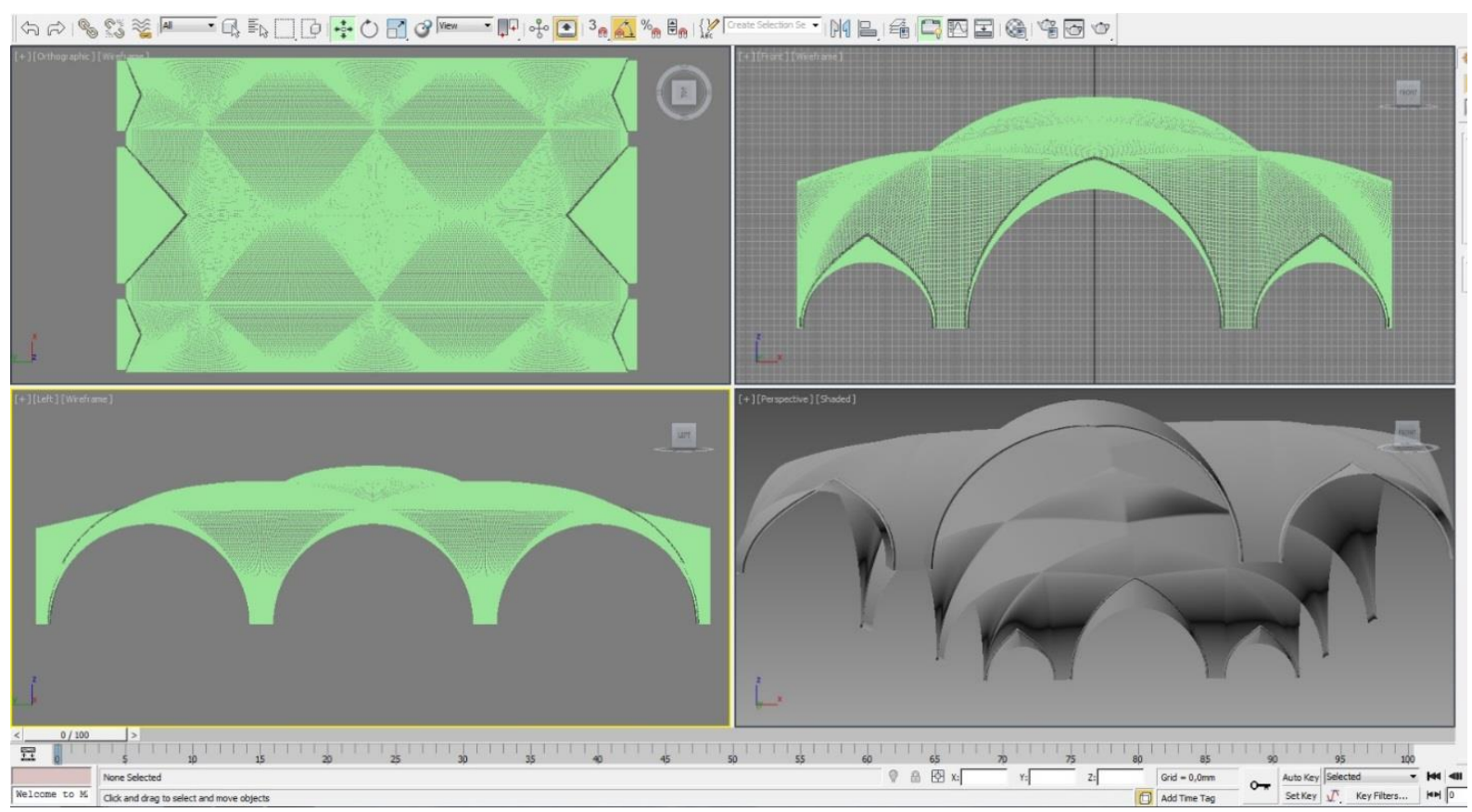

Рис. 5. Моделирование сводов потолка главного зала Трапезной палаты

Все стены главного зала Трапезной палаты имеют арочные и составные от арок отверстия, поэтому наиболее подходящим методом моделирования был комбинированный тип моделирования с помощью сплайнов и последующим применением модификатора выдавливания «Extrude». Методами полигонального и сплайнового моделирования были созданы столбы и лепка. Обрамление потолка было создано из граней поверхности потолка. Рендер модели показан на рис. 6.

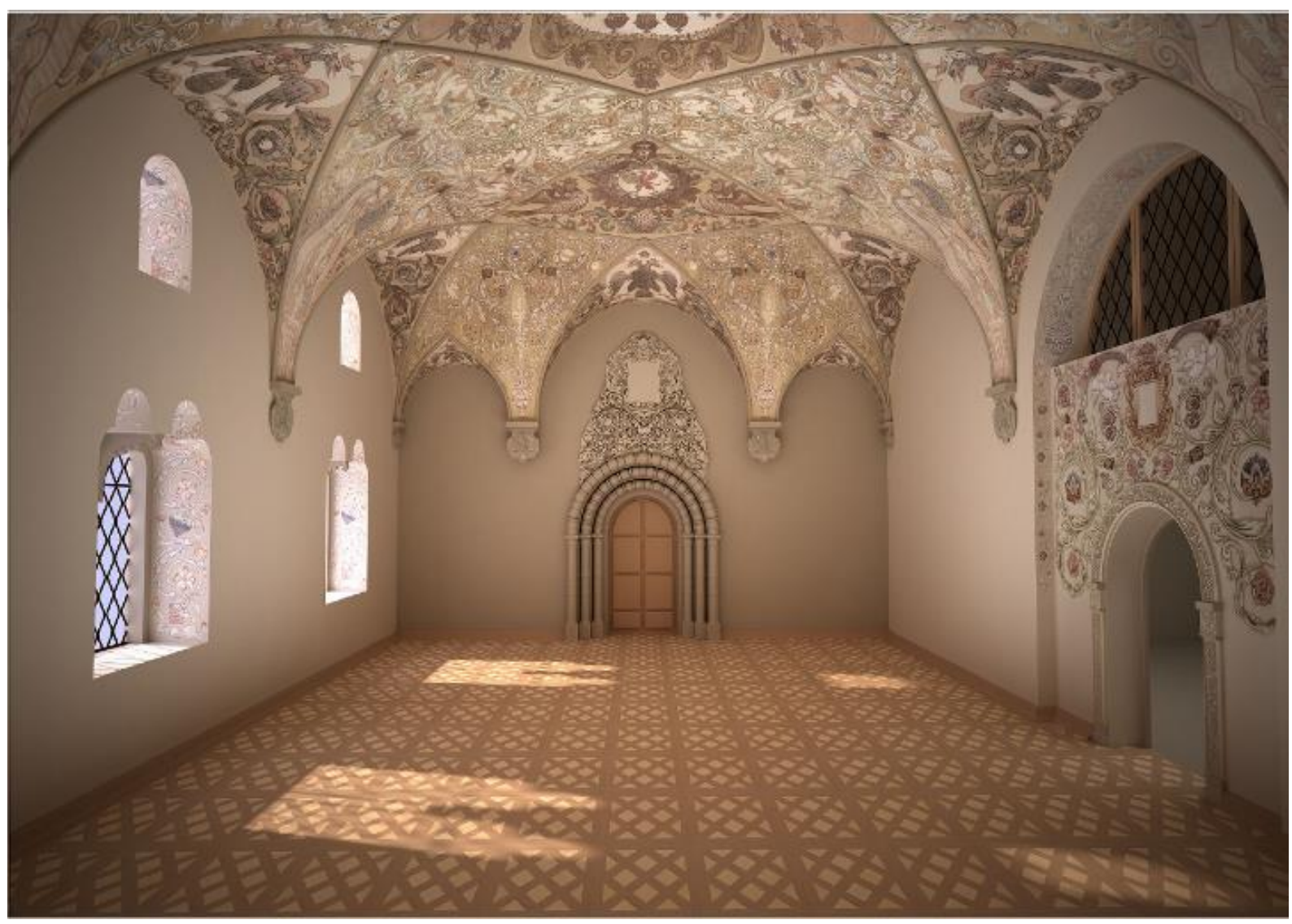

Рис. 6. Виртуальная реконструкция 2015 года (автор - Е. Акулаева) 
В 2016 году студентами 3 и 2 курсов мастерской церковно-исторической живописи СанктПетербургской Академии художеств под руководством А. Крылова на основании геометрически корректных разверток, полученных в результате виртуальной реконструкции, были созданы эскизы росписей сводов Трапезной палаты. Полученные плоскостные изображения были использованы в созданных 3D моделях (рис. 7). Таким образом, виртуальная реконструкция позволяет оценить конкретное колористическое и тональное решение, предложенное автором, увидев его в пространстве [5]. В дальнейшем можно использовать выбранные эскизы для создания реставрационного картона в масштабе $1 / 1$.

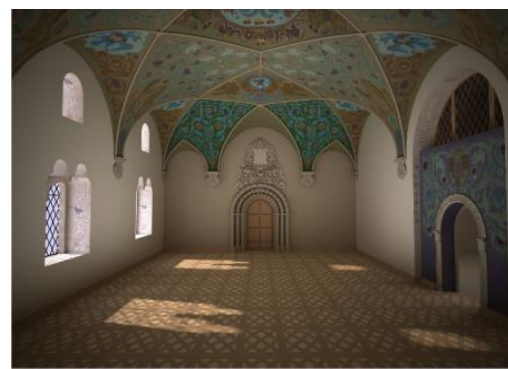

a

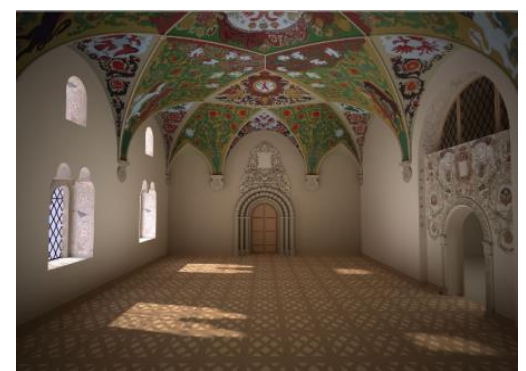

б

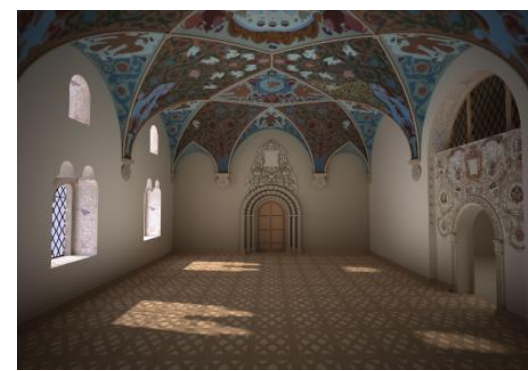

B

Рис. 7. Цветовые решения росписей потолка, предложенные в 2016 году студентами Р. Шуваловым (а), В. Сухоруковым (б), А. Хабаровым (в)

\section{3. Интерактивное приложение для просмотра трёхмерной реконструкции интерьера}

В 2016 году на основе трехмерной модели интерьера Трапезной палаты было создано интерактивное приложение с помощью программного пакета Unity 5, предназначенное для просмотра в шлемах и гарнитурах виртуальной реальности [6]. Пользователь может перемещаться по пространству трапезной и осматривать интерьер с любого ракурса. В качестве интерактивных элементов использованы пасхальные яйца с мотивами росписей, размещенные на подоконнике (рис. 8). При выборе определенного элемента зритель оказывается в интерьере Трапезной, решенном в соответствующем колорите.

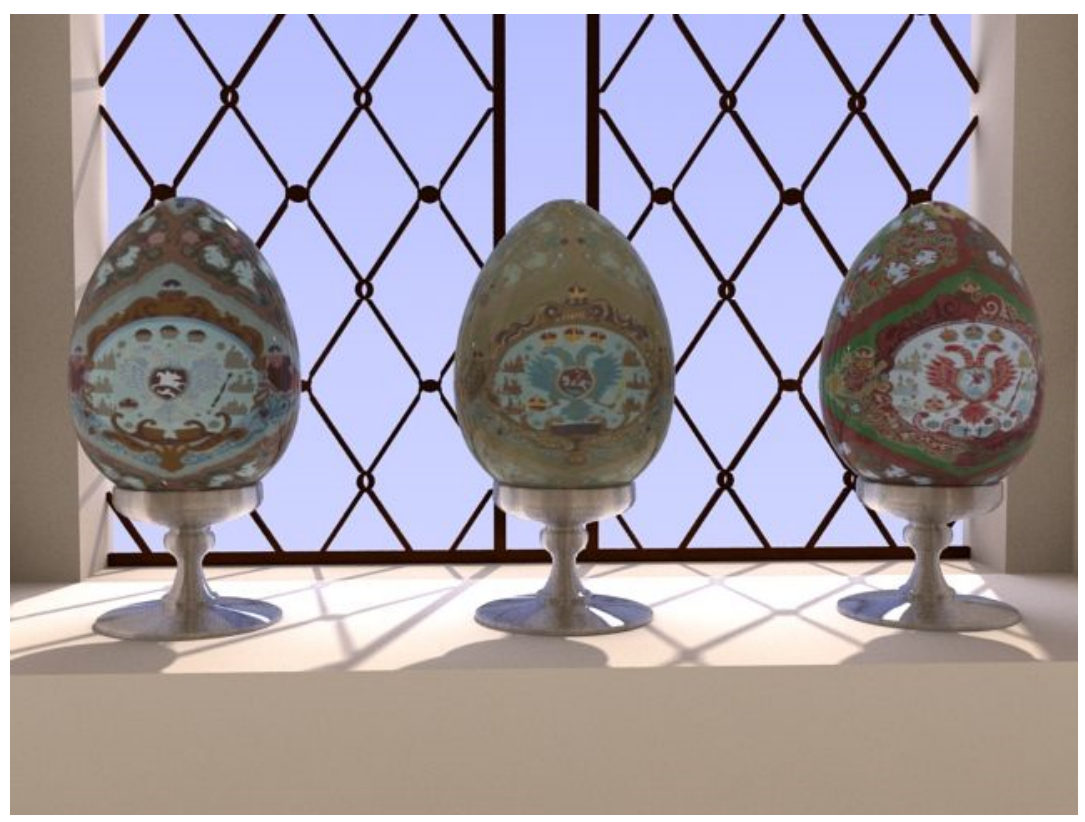

Рис. 8. Элементы интерфейса в виде пасхальных яиц

Для реализации интерактивности и возможности перемещения по сцене с помощью направления взгляда в Unity-приложении были использованы подключаемая библиотека Fibrum SDK и собственный программный код на языке C\#. Приложение было протестировано на шлемах Oculus Rift DK1 и DK2, а также в гарнитуре Samsung Gear VR со смартфоном Samsung S6 Edge, и гарнитуре Homido со смартфоном Sony Xperia Z2.

International Culture \& Technology Studies, Vol. 2, No. 4 
В 2018 году была разработана браузерная версия приложения с реконструкцией Трапезной палаты, использующая технологию WebGL (рис. 9). Виртуальная модель для этого приложения экспортирована из $3 \mathrm{ds}$ Мах в формат .obj, описывающий геометрию объектов и связанный с ним формат .mtl, позволяющий задавать свойства материалов и текстур. Средствами библиотеки Three.js реализована отрисовка 3D модели и интерактивная часть, позволяющая ознакомиться с деталями интерьера. Интерфейс браузерной версии функционально повторяет возможности приложения для гарнитуры виртуальной реальности: пользователь может перемещаться в трёхмерном пространстве и переключать варианты оформления потолка Трапезной палаты, при помощи мыши меняя направление "взгляда".

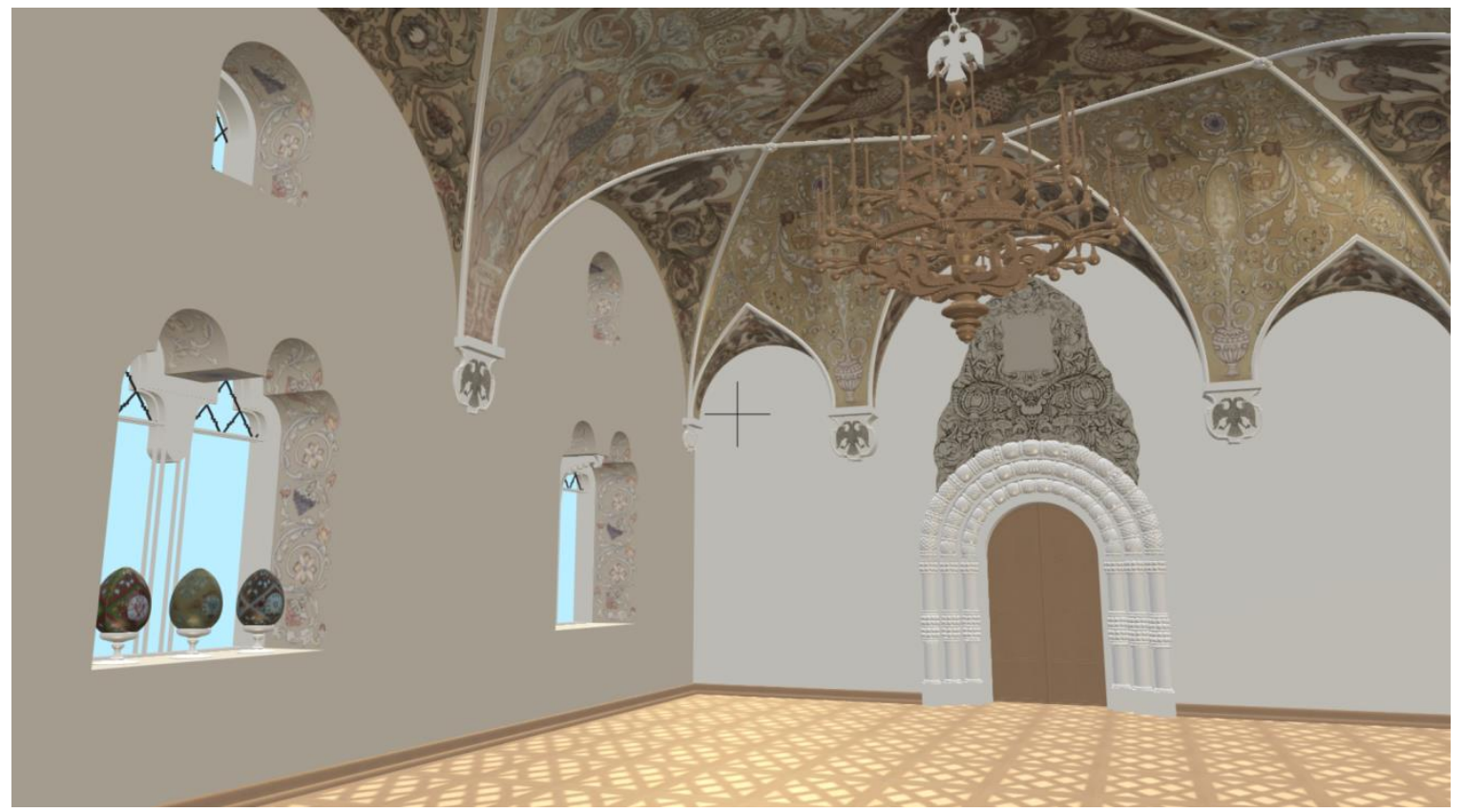

Рис. 9. Интерактивное приложение, реализованное с использованием технологии WebGL

В русских преданиях есть рассказ о Граде Китеже - городе, становящемся невидимым и открывающемся только тем, кто обладает возможностью не просто смотреть, но видеть. Так и Русский городок открывается сейчас только при определенных усилиях. Подобно тому, как в начале XX века с помощью новых для того времени строительных технологий создатели Федоровского городка пытались вдохнуть новую жизнь в традиционные художественные формы, так и в XXI веке виртуальная реконструкция утраченных объектов позволяет вернуть их в культурный контекст.

Данная работа поддержана в рамках проекта «Мультимедийная информационная система «Архитектурно-художественный комплекс Феодоровский городок в Царском селе как пример Русского стиля» » (Грант 17-04-12034, Российский гуманитарный научный фонд). Авторы работы выражают благодарность Царкосельской иконописной мастерской в лице Г.Б. Майоровой, архитектурной мастерской под руководством И.П. Шмелева в лице А.А. Акуловой, руководителю мастерской реставрации церковной живописи Академии художеств профессору А.К. Крылову, музею-институту семьи Рерихов в лице В.Л. Мельникова.

\section{Литература}

[1] Королев Н. Н., Шабарова Ю. В. Русский городок Царского Села. Китеж ХХ века: Иллюстрированная история Федоровского городка и «Общества возрождения художественной Руси». СПб - Царское Село, 2010. C. 24-25, 34.

[2] Исакова Е.В. Идеология Русского стиля в творчестве С.С. Кричинского. /Н.К. Рерих и его современники. Архитекторы и архитектура. Рериховское наследие. Труды конференции VIII: СПб, 2011. C. 194-198.

[3] Sopronenko L., Akulaeva E., The Virtual Reconstruction of the Interior of Refectory Feodorovsky Town in Tsarskoye Selo // EVA 2015 SAINT PETERSBURG. Electronic Imaging \& the Visual Arts INTERNATIONAL CONFERENCE, St. PETERSBURG, JUNE 24th-25th, 2015 Conference Proceedings. SPb ITMO University, 2015. P. 175-181.

Культура и технологии, Том 2, № 4 
[4] Крылов А.К. Колористический символизм древнерусской стенописи (статьи, исследования, заметки).: СПб, 2011. С. 494-503.

[5] Sopronenko L., Akulaeva E., Lavrov A. Technologies of immersion in virtual reality using for the evaluation of different color solutions for Feodorvsky Gorodok refectory 3d-reconstruction // EVA 2016 Saint Petersburg: Electronic Imaging and the Visual Arts. 2016, pp. 105-109.

[6] Sopronenko L.P., Korpan L.M., Lavrov A.V., Balkanskii A.A. Russian style: from creation to virtual reconstruction. On the centenary of Fedorovsky gorodok in Tsarskoye Selo // 4rd International Multidisciplinary Scientific Conference on Social Sciences and Arts, SGEM 2017, Vol. 1, No. 5, pp. 261-268. DOI:10.5593/SGEMSOCIAL2017/HB51/S17.032

\title{
Use of multimedia technologies for interactive 3D reconstruction of the interior of Feodorvsky Gorodok Refectory
}

\author{
L.P. Sopronenko ${ }^{1}$, A.V. Lavrova ${ }^{1}$, A.A. $\operatorname{Smolin}^{1}$, V.L. Melnikov ${ }^{2}$ \\ ${ }^{1}$ ITMO University, Russia \\ ${ }^{2}$ Saint-Petersburg State Roerich Family Museum and Institute, Russia
}

\begin{abstract}
The work is devoted to the virtual reconstruction of the lost interior of the Refectory of the Fedorovsky Gorodok in Tsarskoye Selo. The use of archival materials, fixation of architectural measurements and analysis of similar in style architectural objects ensure the authenticity of the reconstruction. The 3D model was created using Autodesk 3ds Max. The interactive application for virtual-reality headsets was developed at Unity engine, and browser-based version of application was implemented with WebGL using the library Three.js.
\end{abstract}

Keywords: Russian style; color solutions of murals; vaults with Monier system, virtual technologies

\section{References}

[1] Korolev N. N., Shabarova Y. V. Russkiy gorodok Tsarskogo Sela. Kitezh 20 veka [Russian Town of Tsarskoye Selo. Kitezh of $20^{\text {th }}$ Century], St.Petersubrg, 2010. PP. 24-25, 34.

[2] Isakova E.V. Ideologia russkogo stil'a v tvorchestve S.S. Krichinskogo [Ideology of Russian style in the works of S. S. Krichinsky]. Proceeding of the $8^{\text {th }}$ conference "Roerich's legacy": Architects and architecture: St.Petersubrg, 2011. PP. 194-198.

[3] Sopronenko L., Akulaeva E., The Virtual Reconstruction of the Interior of Refectory Feodorovsky Town in Tsarskoye Selo // EVA 2015 SAINT PETERSBURG. Electronic Imaging \& the Visual Arts INTERNATIONAL CONFERENCE, St. PETERSBURG, JUNE 24th-25th, 2015 Conference Proceedings. SPb ITMO University, 2015. P. 175-181.

[4] Krylov A.K. Koloristicheskiy simvolizm drevnerusskoy stenopisi [Coloristic symbolism of the old Russian wall painting]: St.Petersubrg, 2011. PP. 494-503.

[5] Sopronenko L., Akulaeva E., Lavrov A. Technologies of immersion in virtual reality using for the evaluation of different color solutions for Feodorvsky Gorodok refectory 3d-reconstruction // EVA 2016 Saint Petersburg: Electronic Imaging and the Visual Arts. 2016, pp. 105-109.

[6] Sopronenko L.P., Korpan L.M., Lavrov A.V., Balkanskii A.A. Russian style: from creation to virtual reconstruction. On the centenary of Fedorovsky gorodok in Tsarskoye Selo // 4rd International Multidisciplinary Scientific Conference on Social Sciences and Arts, SGEM 2017, Vol. 1, No. 5, pp. 261-268. DOI:10.5593/SGEMSOCIAL2017/HB51/S17.032 